\title{
Modulation of BAG-1 Expression Alters the Sensitivity of Breast Cancer Cells to Tamoxifen
}

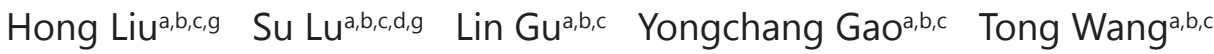 \\ Jing Zhao a,b,c Jianyu Rao ${ }^{d}$ Jun Chen ${ }^{e}$ Xishan Hao ${ }^{a, b, c}$ Shou-Ching Tang ${ }^{c, f}$
}

aKey Laboratory of Breast Cancer Prevention and Therapy, Tianjin Medical University, Ministry of Education, ${ }^{b} K e y$ Laboratory of Cancer prevention and Therapy, 'Tianjin Medical University Cancer Institute and Hospital, Tianjin, China; ${ }^{\mathrm{d} D e p a r t m e n t}$ of Pathology and Laboratory Medicine, University of

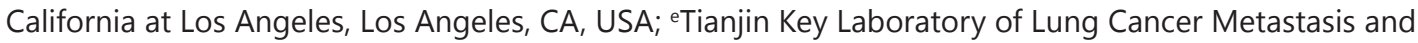
Tumor Microenvironment; Tianjin Lung Cancer Institute, Tianjin Medical University General Hospital, Tianjin, China; ${ }^{\mathrm{f} G e o r g i a}$ Regents University Cancer Center, Augusta, GA USA; ${ }^{9 H}$ Hong Liu and Su Lu contributed equally to this paper

\section{Key Words}

Breast cancer • Apoptosis • Hormonal therapy • TAM resistance • BAG-1

\begin{abstract}
Background: BAG-1 (bcl-2 associated athanogene) is a multifunctional protein that protects cells from a wide range of apoptotic stimuli including radiation, hypoxia and chemotherapeutic agents. Overexpression of cytoplasmic BAG-1 has been associated with the increased survival and decreased response to treatment with tamoxifen (TAM) in breast cancer. We attempted to assess the expression of BAG-1 in the human breast cancer cells that are resistant to treatment with 4-OH TAM and effect of altered BAG-1 expression on their sensitivity to 4-OH TAM. Methods: BAG-1 expression was examined in the MCF-7 cells that became resistant to 4-OH TAM. The 4-OH TAM-resistant MCF-7 cells were then transfected with the BAG-1 siRNA and the 4-OH TAM-sensitive MCF-7 cells with the plasmids carrying the human BAG-1 isoformspecific expression constructs respectively to investigate the effect of BAG-1 on the TAMinduced apoptosis. Results: Our results showed that the TAM-resistant MCF-7 (TAMR/MCF-7) cells expressed higher level of BAG-1 than that of the MCF-7 cells. Down-regulation of BAG-1 significantly enhanced the sensitivity of the TAMR/MCF-7 cells to TAM treatment. Additionally, we found that BAG-1 p50 was the only isoform that inhibited the TAM-induced apoptosis in the MCF-7 cells, while the other isoforms had little effect. Conclusion: Our study indicated that up and down regulations of the BAG-1 expression were associated with the decreased and increased sensitivity to 4-OH TAM in the estrogen receptor-positive (ER+) human breast cancer cell line MCF-7 respectively, and distinct isoforms of BAG-1 had different anti-apoptotic ability in breast cancer cells treated with the 4-OH TAM.
\end{abstract}


Liu et al.: BAG-1 Affects the Sensitivity of Breast Cancer Cells to Tamoxifen

\section{Introduction}

Tamoxifen (TAM) is frequently used for the treatment of both early and advanced estrogen- and/or progesterone-receptor (ER and/or PR) positive breast cancer [1]. Resistance to TAM occurs in 30 to $50 \%$ cases of the ER+ breast cancer [2]. Approximately $30 \%$ of ER-positive breast cancers do not respond to TAM treatment (de novo resistance), while majority of tumors eventually develop resistance over time despite the initial response (acquired resistance) [3]. Several hypotheses have been put forward to explain the development of TAM resistance, including the changes in the expression of ER, alterations in co-regulatory proteins, interference from other growth factor pathways and excess estrogen synthesis by breast, ovary or peripheral adipose tissues [4].

BAG-1 (bcl-2 associated athanogene) is a multifunctional protein that interacts with a number of molecules to regulate the diverse biological processes including apoptosis, proliferation, signal transduction and transcription [5]. We and others have observed the frequent expression of BAG-1 in a variety of tumor cell lines and cancer tissues [6-12] and the increased expression of BAG-1 in breast cancer compared to that of the normal breast tissues [8, 13-18]. In breast cancer cell lines, BAG-1 prevented cells from undergoing apoptosis induced by radiation, chemotherapy and stress $[13,19]$. We have noted the correlation of BAG-1 expression with other prognostic markers in breast cancer such as Bcl2, p53, differentiation, ER and PR in invasive breast cancer [13]. Finally, Cutress et al. have demonstrated that BAG-1 enhanced the transcriptional activity of both ER $\alpha$ and ER $\beta$ by four folds in breast cancer cell line MCF-7 [20].

Given the significance of endocrine therapy in breast cancer and the possible impact of BAG-1 on ER function and responsiveness to TAM, BAG-1 may serve as a valuable predictive biomarker for responsiveness or resistance to anti-hormone therapy in order to improve the selection of breast cancers for optimal endocrine therapy. Consequently, we assessed the association between the expression of BAG-1 and the sensitivity to 4-OH TAM in the human breast cancer cells, and further investigated the effect of BAG-1 on the TAM-induced apoptosis by altering the expression of BAG-1 in the MCF-7 cells. In addition, we evaluated the role of individual BAG-1 isoform in modulating the TAM-induced apoptosis through transfecting the MCF-7 cells with the plasmids carrying the human BAG-1 isoform-specific expression constructs.

\section{Materials and Methods}

\section{Cell culture}

MCF-7 breast cancer cells were routinely cultured in the RPMI medium containing $10 \%$ fetal bovine serum (FBS), 100units/ml penicillin and $100 \mu \mathrm{g} / \mathrm{ml}$ streptomycin. The TAM-resistant MCF-7cells (TAMR/ MCF-7) were established using the methodology reported before [21]. Briefly, the MCF-7 cell monolayers were washed thoroughly with the phosphate buffered saline (PBS), and transferred to phenol red-free RPMI medium containing 10\% charcoal-stripped, steroid-depleted FBS, antibiotics and 4-hydroxytamoxifen (4$\mathrm{OH} \mathrm{TAM}, 10^{-7} \mathrm{M}$ in ethanol). The culture media was replaced every the other day and medium was maintained in a humidified atmosphere with $5 \% \mathrm{CO}_{2}$ in air at $37^{\circ} \mathrm{C}$. The cell cultures were passaged with $0.05 \%$ trypsin when $70 \%$ confluency was reached. Cells were continuously exposed to the treatment regimen for 6 months.

MTT cell viability assay

To determine the cell viability, the cells were plated at a density of $10^{4}$ cells/well in 96 -well plates. MCF7 and TAMR/MCF-7 cells were incubated in the medium containing 10\% charcoal-stripped steroid-depleted FBS with or without of 4-hydroxytamoxifen (0-1000nM) for 48 hours. After treatment, the medium was replaced with $200 \mu \mathrm{l}$ RPMI containing $0.5 \mathrm{mg} / \mathrm{ml} \mathrm{MTT}$ and the plates were incubated for 4 hours at $37^{\circ} \mathrm{C}$. The cell medium was then removed and the formazan crystals were dissolved by $200 \mu$ dimethylsulfoxde/well. The absorbance was measured on a spectrophotometer microplate reader at $540 \mathrm{~nm}$. The cell viability was assigned as the relative ratios to the untreated control cell. 
Growth assay

Cell samples were grown for 8 days in the medium containing 4-OH TAM (100nM). Cells were dispersed by trypsin treatment, and the cell number was then measured using a Coulter counter. All experiments were performed at least three times.

RNA extraction and RT-PCR

Total RNA was extracted from cells using the Trizol reagent (Invitrogen, CA, USA) following manufacturer's instructions, and quantified using the UV spectrophotometer (Beckman Coulter, CA, USA). Total RNA was reverse transcribed into single stranded cDNAs using the PrimeScript RT reagent kit (Takara, Japan) using the manufacturer's protocol. $0.5 \mu \mathrm{g}$ of cDNAs was used for subsequent $20 \mu \mathrm{l}$ PCR amplification. The PCR was performed using the BAG-1 specific primers (forward 5'-GTTCTTTGGATGGAGCCTGTG-3' reverse 5'-TGCCTGCTTTACTCATTCTGGTG-3') and $\beta$-actin specific primers as a positive control. The PCR conditions were as follows: $95^{\circ} \mathrm{C}$ for $10 \mathrm{~min}, 94^{\circ} \mathrm{C}$ for $45 \mathrm{sec}$, the appropriate annealing temperature for 45 sec, $72^{\circ} \mathrm{C}$ for $1 \mathrm{~min}$ and a final extension of $72^{\circ} \mathrm{C}$ for $5 \mathrm{~min}$. PCR products were resolved on $1 \%$ agarose gels and stained with ethidium bromide. For real-time PCR, a Bio-Rad iQ ${ }^{\mathrm{TM}}$ SYBRR Green Supermix and a myiQ ${ }^{\mathrm{TM}}$ machine were used. The cycling conditions were $50^{\circ} \mathrm{C}$ for $2 \mathrm{~min}, 95^{\circ} \mathrm{C}$ for $10 \mathrm{~min}$, followed by 40 cycles of $95^{\circ} \mathrm{C}$ for $15 \mathrm{sec}$ and $60^{\circ} \mathrm{C}$ for $30 \mathrm{sec}$. Each sample was run in triplicate for each gene. The quantities of amplified genes were analyzed by comparison of $2^{-\Delta \Delta \mathrm{CT}} \times 100 \%$ [22]. All gene primers were obtained from the Sangon Biotech Co., Ltd. (Shanghai, China).

\section{Western blot analysis}

Cultured cells were washed with the ice-cold PBS, and then lysed with the lysis buffer supplemented with $1 \times$ protease inhibitor mix. The mixture was centrifuged for $30 \mathrm{~min}$ at a speed of $12,000 \mathrm{~g}$ and the supernatant fraction was then collected and stored at $-80^{\circ} \mathrm{C}$. The total protein concentration for each sample was quantified by a Bio-Rad kit (Bio-Rad, CA, USA). Equal amounts of proteins from each extract were boiled with Laemmli's sample buffer containing $5 \% \beta$-mercaptoethanol for denaturation. The sample proteins were separated by SDS-PAGE and blotted onto a polyvinyl difluoride (PVDF) membrane. The PVDF membrane was blocked with 5\% defat milk power in TBST for 2 hours at room temperature. Then the membrane was incubated with the primary antibody at $4^{\circ} \mathrm{C}$ overnight and with secondary antibody at room temperature for 2 hours. ECL reagents were used to visualize the positive bands which were detected by ChemiDoc MP (Bio-Rad, CA, USA).

\section{Transfection}

Construction of plasmids containing the BAG-1 p50, p46, p33 was described previously [23, 24], and all recombinant plasmids were confirmed by DNA sequencing. DNA transfection was performed using the Lipofactamine $^{\mathrm{TM}} 2000$ reagent (Invitrogen) according to the manufacturer's protocol. Briefly, $2 \times 10^{5}$ cells / well were seeded into 24-well plates and incubated in medium without antibiotics overnight. Next day, 0.8ug of DNA was mixed with lipofetamine 2000, and the mixture was added to each well containing cells. Stable transfectants were selected by G418 (Gibco) and maintained as cell lines for drug treatment, apoptotic assay, RT-PCR and western blot analysis. The cells were then incubated at $37^{\circ} \mathrm{C}$ in a $\mathrm{CO}_{2}$ incubator for 24 hours. For BAG-1 knockdown, a validated BAG-1 siRNA and a scrambled siRNA as a negative control were used. The BAG-1 siRNA (product NO. siB08715170439) was designed and synthetized by Guangzhou RiboBio Co., Ltd. Briefly, $2 \times 10^{5}$ cells /well in 24-well plates were transfected at a final concentration of $50 \mathrm{nM}$ of BAG-1 siRNA or control siRNA using lipofetamine 2000 (Invitrogen). After incubation, cells were prepared for subsequent assays.

\section{Cell apoptosis analysis}

Treated cells were stained using the Annexin V-FITC Apoptosis Analysis Kit (BD Bioscience, CA, USA) and subjected to flow cytometry (BD Bioscience, CA, USA) to isolate the Annexin V-FITC stained apoptotic cells. Data were analyzed with the WIMDI 2.8 software. The percentage of cells that underwent TAMmediated apoptosis was determined by subtracting the percentage of apoptotic cells in the untreated population from that in the TAM-treated population 
Fig. 1. Overexprssion of BAG-1 in the TAMR/ MCF-7 cells. (A) Growth curves of TAMR/MCF7 and MCF-7 cells in the presence of 4-OH TAM (100nM). Cells were treated with 4-OH TAM at the concentration of $100 \mathrm{nM}$ for 8 days and the cells number was counted each day. Each experiment was repeated three time and the results were expressed as means \pm S.D. (B) BAG-1 mRNA expression. BAG-1 mRNA expression level in MCF-7 and TAMR/MCF-7 cells were determined by RT-PCR. (C) Western blot analysis of BAG-1. Whole cell lysates were prepared and analyzed for protein expression of BAG-1 with an antibody that recognized all isoforms of BAG-1 protein. (D) Real-time PCR analysis of BAG-1 expression in TAMR/MCF-7 and MCF-7 cells. Each sample was run in triplicate for each gene. The quantities of amplified genes were analyzed by comparison of 2 -average $\Delta \Delta \mathrm{CT}$ x $100 \%$.



\section{Results}

Increased expression of BAG-1 in the TAM-resistant breast cancer cells

The acquisition of resistance to TAM in the TAMR/MCF-7 cells was confirmed by comparing the growth curves of the TAMR/MCF-7 and MCF-7 cells cultured in the presence of 4-OH TAM (Fig. 1A). The expression levels of BAG-1 in both TAMR/MCF-7 and control MCF-7 cells were determined by RT-PCR (Fig. 1B) and western blot analysis (Fig. 1C). As shown in Fig. 1D, the real-time PCR results were consistent with that of the RT-PCR and western blot, with almost two-fold increase in BAG-1 expression in the TAMR/MCF-7 cells compared to that of the MCF-7 cells.

Knockdown of BAG-1 by siRNA increased TAM-induced apoptosis in the TAMR/MCF-7 cells

Total cellular RNA and protein were extracted to verify changes in BAG-1 expression in the siRNA transfected Tamoxifen resistant cells using the real-time PCR and western blot. BAG-1 mRNA and protein expression were dramatically decreased in the TAMR/MCF-7 cells transfected with the BAG-1 siRNA compared with that of the siRNA-transfected negative control cells (Fig. 2A, Fig. 2B). As illustrated in Fig. 3A TAMR/MCF-7 cells transfected with the BAG-1 siRNA showed enhanced sensitivity to tamoxifen at the concentration of $100 \mathrm{nM}$ ( $47.70 \%$ vs. $97.89 \%, \mathrm{p}<0.05)$ and $1000 \mathrm{nM}(38.57 \%$ vs. $98.00 \%, \mathrm{p}<0.05)$ compared with the control. Additionally, we used Annexin-V FITC flow cytometry to detect the apoptotic cells after the treatment with 4-OH TAM for 48 hours. We consistently observed significantly increased apoptosis induced by the 4-OH TAM in the TAMR/MCF-7 cells transfected with the BAG-1 siRNA $(16.1 \pm 1.2 \%$ vs. $0.8 \pm 0.3 \%$, p<0.05, Fig. $3 \mathrm{~B})$ compared to that of the control cells. 
Fig. 2. Knockdown of BAG-1 in the TAMR/ MCF-7 cells. (A) Western blot analysis of the BAG-1 protein expression in TAMR/ MCF-7 cells 48 hours after transfection. Whole cell lysates were prepared and analyzed for protein expression of BAG1 with an antibody that recognized all isoforms of BAG-1 protein. (B) Real-time PCR analysis of BAG-1 expression in TAMR/ MCF-7 cells 48 hours after transfection. BAG-1 mRNA expression was determined in triplicate.
A

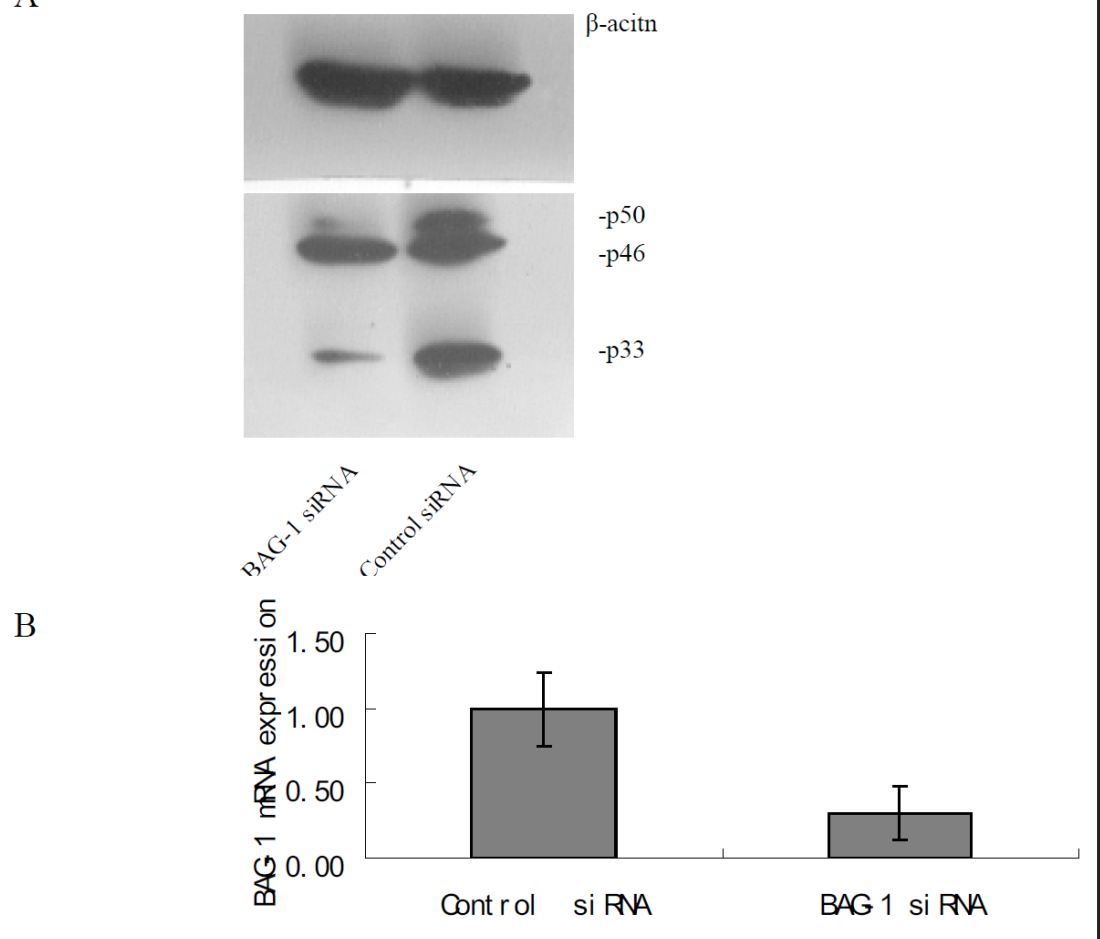

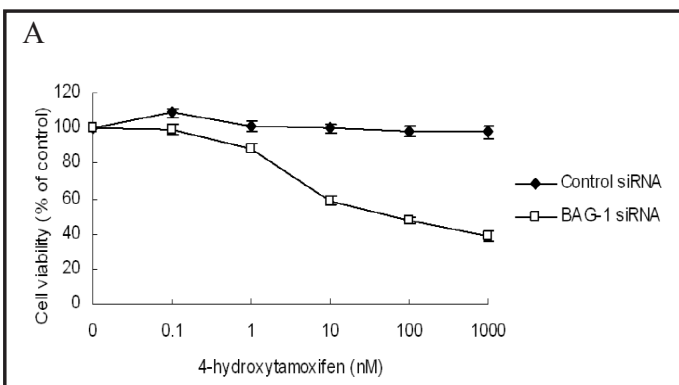

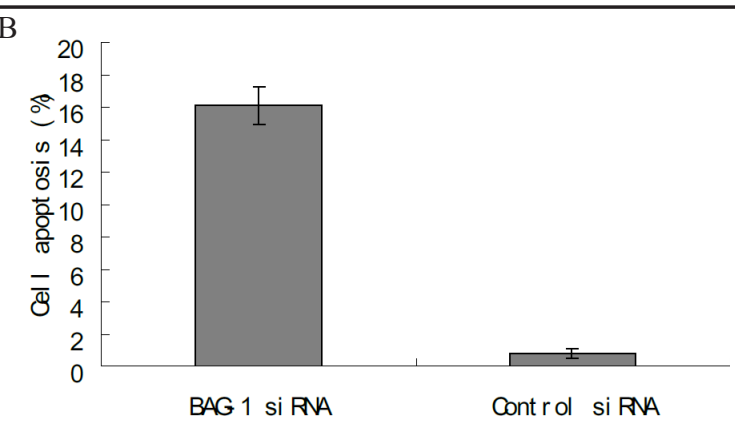

Fig. 3. Effect of BAG-1 expression on response to TAM in the TAMR/MCF-7 cells. (A) MTT cell viability assay. After transfection with the BAG-1 siRNA or control siRNA for 48 hours, the TAMR/MCF-7 cells were treated with 4-OH TAM (0.1-1000nM) for 48 hours, and cell viability were then assessed using the MTT assay. Data were expressed as the means \pm S.D. of triplicate wells and represented three independent experiments. (B) Apoptosis assay by flow cytometry. After transfection with the BAG-1 siRNA or control siRNA for 48 hours, the TAMR/MCF-7 cells were treated with 4-OH TAM (1000nM) for 48 hours. Cell apoptosis were determined using the Annexin V-FITC apoptosis kit.

\section{Overexpression of BAG-1 inhibited TAM-induced apoptosis in the MCF-7 cells}

As shown in Figure 4A, MCF-7 cells transfected with each of the isoform-specific constructs expressed expected protein products. The mRNA levels of the specific BAG-1 isoforms were dramatically enhanced in the MCF-7 cells after transfection when compared with neo-transfected control cells (Fig. 4B).

Our results revealed that the MCF-7 cells transfected with the BAG-1 p50 exhibited significant resistance to apoptosis induced by $4-\mathrm{OH}$ TAM at the concentrations of $100 \mathrm{nM}$ (6.36 \% vs. $12.57 \%, \mathrm{p}<0.05)$ and $1000 \mathrm{nM}(8.77 \%$ vs.16.77\%, p < 0.05). However, the cells transfected with the BAG-1 p46 and p33 showed no significant change in apoptosis in 
Fig. 4. Effect of BAG-1 isoforms overexpression on apoptosis in the MCF-7 cells. (A) Overexpression of BAG-1 isoforms in MCF-7 cells. MCF-7 cells were transfected with the BAG-1 isoform-specific expression constructs or plasmid pCR3.1 as a control, and the expression of BAG-1 was analysis by western blot. (B) Real-time PCR analysis of the overexpression of BAG-1 isoforms in the MCF-7 cells after transfection. BAG-1 mRNA expression was determined in triplicate. (C) Effect of BAG-1 isoforms expression on MCF-7 cell apoptosis induced by $4-\mathrm{OH}$ TAM (100nM and 1000nM). Cells $\left(0.5 \times 10^{4}\right.$ cells $/$ well $)$ were treated with 4-OH TAM of $100 \mathrm{nM}$ and $1000 \mathrm{nM}$ for 48 hours. The results were presented as the proportion of apoptotic cells over cells treated with TAM minus the proportion of apoptotic cells of the untreated cells. Data were expressed as the means \pm S.D. of triplicate wells and represented three independent experiments, and * $\mathrm{P}<0.05$ vs. Neo control.

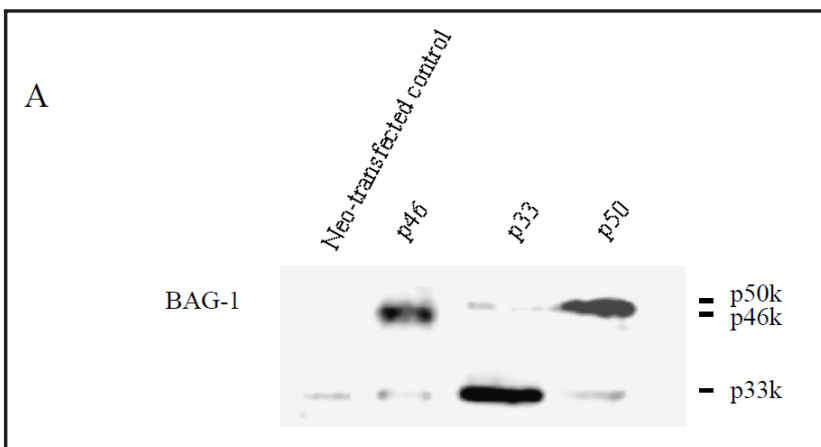

$B$

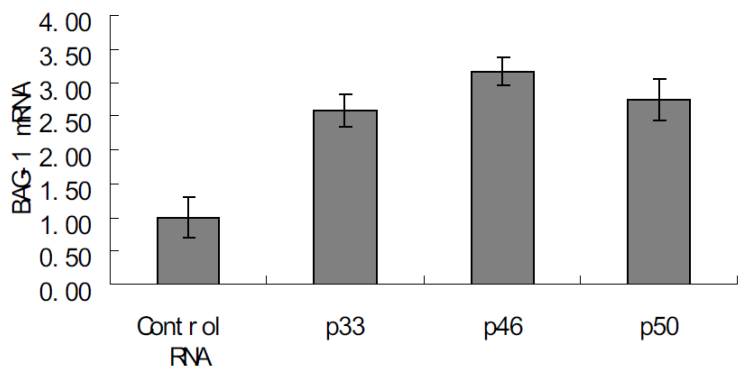

C

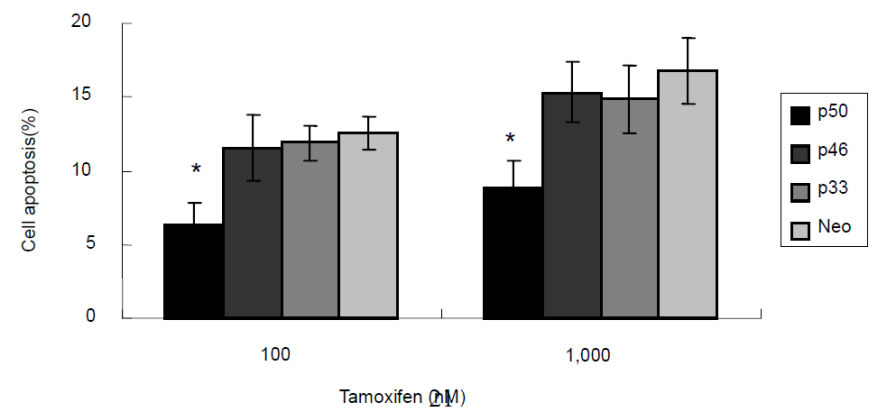

response to $4-\mathrm{OH}$ TAM treatment $(100 \mathrm{nM}$ : $11.56 \%, 11.89 \%$ vs. $12.57 \%, \mathrm{P}>0.05 ; 1000 \mathrm{nM}$ : $15.34 \%, 14.87 \%$ vs. $16.77 \%, \mathrm{P}>0.05)$.

\section{Discussion}

Overexpression of BAG-1 has been found in many tumor cell lines, tumor tissues and drug resistant cancer cells $[9,11,25]$ and correlated with the expression of other prognostic markers such as ER, PR, Bcl-2 and p53 [9, 11, 25]. We first noted the prognostic value of BAG1 expression in invasive breast cancer and the association of the nuclear BAG-1 expression with the decreased survival [17]. Consistently, cytoplasmic BAG-1 expression was later found to be associated with the increased survival in breast cancer [17] and lung cancer [11]. The prognostic value of BAG-1 was further tested in the study by Paik et al [26]. BAG1 had been included as one of the 16 genes in the Oncotype DX test, now widely used in the prognosis of node- and ER/PR + early breast cancer in USA. Cutress et al reported a strong relationship between the increased BAG-1 expression and improved outcome in breast cancer patients treated with TAM [20]. This finding was later confirmed by another study which demonstrated that the high level of BAG-1 expression may indicate enhanced sensitivity to TAM in the ER+ invasive ductal carcinoma [27]. Taken together, these reports 
suggest that BAG-1 may serve as a favorable predictive biomarker for the responsiveness to hormonal therapy such as TAM. Overexpression of BAG-1 should therefore sensitize the breast cancer cells to 4-OH TAM. In the present study we compared the expression of BAG-1 in the TAM-resistant cells TAMR/MCF-7 and the TAM-sensitive breast cancer cells MCF-7. To our surprise, our study showed that both BAG-1 mRNA and protein expression levels were significantly enhanced in the TAMR/MCF-7 cells. To confirm our observation that BAG-1 overexpression may lead to decreased sensitivity to treatment with TAM, we further used the siRNA to downregulate the expression of BAG-1 in the TAM-resistant cells TAMR/MCF-7, and found an increased sensitivity to TAM treatment in the siRNA-transfected cells compared to that of the Neo-transfected control. To further explore if the opposite was true and to investigate the specific function of individual BAG-1 isoforms, we transfected the recombinant plasmids carrying the isoform-specific expression constructs into the TAMsensitive breast cancer cell line, MCF-7. As expected, transfection of BAG-1 led to increased resistance to treatment with TAM. In addition, different BAG-1 isoforms have distinct antiapoptotic function in the MCF-7 cells. Only BAG-1 p50 was able to inhibit the TAM-induced apoptosis in the MCF-7 cells transfected with each of the BAG-1 isoforms respectively. Our finding provided the first laboratory evidence of the negative predictive value of BAG-1 in the responsiveness to treatment with TAM in breast cancer. Our data is consistent with several other studies demonstrating the association of the BAG-1 overexpression and resistance to therapy. Overexpression of BAG-1 has been reported to inhibit the activation of caspases and apoptosis induced by chemotherapeutic agents, radiation and growth factor withdrawal [28, 29]. Townsend et al reported that BAG-1S protected the cells from the long-term growthinhibitory effects of a range of cellular stresses including cytotoxic drugs, radiation, and hypoxia. We have previously used BAG-1 siRNA to downregulate the expression of BAG1 in the human lung adenocarcinoma cell line A549, and found a significantly enhanced sensitivity to cisplatin-induced apoptosis in the BAG-1 siRAN transfected cells [30]. Similar observations were made in the MCF-7 breast cancer cells transfected with the BAG-1 siRNA and treated with doxorubin, docetaxel and 5-FU [24, 31] and in the human cervical cancer cell lines treated with cisplatin staurosporine, paclitaxel and doxorubicine [23]. Our paradoxical finding of BAG-1 being a positive prognostic yet negative predictive biomarker in breast cancer is important clinically. A parallel yet opposite analogy can be made with the expression of HER-2, which has been associated with the adverse prognosis for survival yet favorable response to anti-HER-2-based targeted therapy in invasive breast cancer. The positive prognostic value of BAG-1 may be explained by its association with the expression of other positive prognostic markers in breast cancer such as ER, PR and Bcl-2. In addition, overexpression of cytoplamic BAG-1 has been associated with the increased survival in breast cancer. BAG-1 p33 is cytoplamic proteins due to its lack of the nuclear localization signals. Townsend et al found a significant positive correlation between the ER status and the expression of cytoplasmic BAG-1 [18]. Cytoplamic BAG-1s are likely to interact with the Bcl-2 which is also a positive prognostic biomarker for breast cancer. Interaction of cytoplasmic BAG-1s with other cytoplamic proteins such as tyrosine kinase HGF/PDGF receptors on outer cell membranes, Bcl-2 on inner cell membranes, cytosolic Hsps and Raf-1 [32] may also has positive impact on the survival of breast cancer. BAG-1 p50 and 46 on the other hand are nuclear proteins due to presence of the nuclear localization signals. Nuclear BAG-1 has been reported to interact with the other hormone-response proteins such as ER and PR. Binding of BAG-1 may affect the function of ER/PR and reduce their binding to TAM. In addition, BAG-1 is known to bind DNA directly to function as a transcription or co-transcription factor [7] to regulate the transcription of genes that may affect the response by ER/PR to TAM treatment. Finally, BAG-1 is known to function as a chaperon that targets its binding proteins to degradation by proteasome. Increased BAG-1 expression may lead to decreased ER/PR protein expression leading to decreased sensitivity to TAM treatment. The negative impact of nuclear BAG-1 on the response to hormonal and chemotherapy will ultimately reduce the survival of breast cancer patients. Indeed, we have previously reported the negative impact of nuclear BAG-1 on the survival of breast cancer [8]. 
BAG-1 isoforms interact with several nuclear hormonal receptors (NHR) and regulate their activity. Froesch et al found BAG-1L, but not BAG-1M or BAG-1S, increased the androgen receptor function [33]. Similarly, BAG-1M and BAG-1L, but not BAG-1S repressed the glucocorticoid receptor activity [34]. Our study showed increased BAG-1 expression in the breast cancer cells that were resistant to TAM. Unfortunately, we did not have the isoform-specific antibodies to detect which BAG-1 isoform was overexpressed in these cells. We also demonstrated by siRNA transfection that reduced BAG-1 expression led to increased apoptosis induced by TAM treatment in the TAMR/MCF-7 cells. Consistently, overexpression of BAG-1 resulted a decreased sensitivity to TAM treatment. More importantly, we were able to further evaluate the role of individual BAG-1 isoform in inhibiting the TAM-induced apoptosis by transfecting the MCF-7 cells with the plasmids carrying the BAG-1 isoformspecific expression constructs. We found that only the BAG-1 p50 isoform increased the viability of the MCF-7 cells in the presence of 4-OH TAM, while p46 and p33 had little effect. Our finding was consistent with a previous study showing that BAG-1L, but not the other BAG1 isoforms, interacted with the ER $\alpha$ and stimulated the estrogen-dependent transcription [20]. In cervical cancer cells, BAG-1 p50, p46 and p33 enhanced the resistance to apoptosis induced by a wide range of reagents including cisplatin, staurosporine, paclitaxel and doxorubicine. BAG-1 p46 isoform resulted the most profound inhibition in apoptosis [23]. In addition, BAG-1 isoforms also had distinct function in modulation the chemotherapeuticinduced apoptosis in breast cancer cells [24]. The different anti-apoptotic function of BAG-1 isoforms may result from the unique N-tuminus of the BAG-1 p50, which was important in its nuclear localization and binding to hormone receptors, transcription factors and certain DNA promoters [33-35]. Finally, the prognostic value of BAG-1 expression in breast cancer was recently confirmed in a prospective cohort from the TansATAC study [36]. Women with higher BAG-1 expression developed $30 \%$ fewer distant recurrences compared to those with low expression. Nuclear BAG-1 expression added more prognostic value in node-positive cases. Our observation indicate that future research on the prognostic and predictive values of BAG-1 expression should be directed to the individual BAG-1 isoform to separate the impact of each BAG-1 on the prognosis and prediction for response to therapy. Furthermore, our finding has significant clinical implication in developing BAG-1-targeted therapy. Since BAG-1 p50 is the only BAG-1 isoforms that is involved in the resistance to treatment with TAM, future efforts should be made to block its production or function.

In summary, we found unexpected overexpression of BAG-1 in the TAM-resistant TAMR/ MCF-7 compared with that of the TAM-sensitive MCF-7 breast cancer cells. Knockdown of the BAG-1 expression significantly enhanced the sensitivity to treatment with TAM in the TAMR/MCF-7 cells transfected with the BAG-1 siRNA. Consistently, overexpression of BAG-1 resulted an increased resistance to TAM treatment. More importantly, BAG-1 p50 was the only isoform that inhibited the MCF-7 cells from apoptosis induced by TAM. Our finding has significant prognostic, predictive and therapeutic implications in developing future targeted therapy against BAG-1, especially the BAG-1 p50.

\section{Conflict of Interests}

All authors declare no conflict of interest.

\section{Acknowledgments}

This work is supported by the funding from Tianjin Research Program of Application Foundation and Advanced Technology (No.10JCZDJC20100) and by the Innovation Funding for graduates of Tianjin Medical University, third phase of the 211 Project for Higher Education (No. 2009GSI09). 
Liu et al.: BAG-1 Affects the Sensitivity of Breast Cancer Cells to Tamoxifen

\section{References}

1 Jordan VC: Fourteenth Gaddum Memorial Lecture. A current view of tamoxifen for the treatment and prevention of breast cancer. Br J Pharmacol 1993;110:507-517.

- Frasor J, Chang EC, Komm B, Lin CY, Vega VB, Liu ET, Miller LD, Smeds J, Bergh J, Katzenellenbogen BS: Gene expression preferentially regulated by tamoxifen in breast cancer cells and correlations with clinical outcome. Cancer Res 2006;66:7334-7340.

-3 Riggins RB, Schrecengost RS, Guerrero MS, Bouton AH: Pathways to tamoxifen resistance. Cancer Lett 2007;256:1-24.

4 Badia E, Oliva J, Balaguer P, Cavailles V: Tamoxifen resistance and epigenetic modifications in breast cancer cell lines. Curr Med Chem 2007;14:3035-3045.

-5 Townsend PA, Cutress RI, Sharp A, Brimmell M, Packham G: BAG-1: a multifunctional regulator of cell growth and survival. Biochim Biophys Acta 2003;1603:83-98.

-6 Kitada S, Andersen J, Akar S, Zapata JM, Takayama S, Krajewski S, Wang HG, Zhang X, Bullrich F, Croce CM, Rai K, Hines J, Reed JC: Expression of apoptosis-regulating proteins in chronic lymphocytic leukemia: correlations with In vitro and In vivo chemoresponses. Blood 1998;91:3379-3389.

7 Yang X, Chernenko G, Hao Y, Ding Z, Pater MM, Pater A, Tang SC: Human BAG-1/RAP46 protein is generated as four isoforms by alternative translation initiation and overexpressed in cancer cells. Oncogene 1998;17:981-989.

8 Tang SC, Shehata N, Chernenko G, Khalifa M, Wang X: Expression of BAG-1 in invasive breast carcinomas. J Clin Oncol 1999;17:1710-1719.

-9 Yang X, Hao Y, Ding Z, Pater A, Tang SC: Differential expression of antiapoptotic gene BAG-1 in human breast normal and cancer cell lines and tissues. Clin Cancer Res 1999;5:1816-1822.

10 Shindoh M, Adachi M, Higashino F, Yasuda M, Hida K, Nishioka T, Ono M, Takayama S, Reed JC, Imai K, Totsuka Y, Kohgo T: BAG-1 expression correlates highly with the malignant potential in early lesions (T1 and T2) of oral squamous cell carcinoma. Oral Oncol 2000;36:444-449.

-11 Rorke S, Murphy S, Khalifa M, Chernenko G, Tang SC: Prognostic significance of BAG-1 expression in nonsmall cell lung cancer. Int J Cancer 2001;95:317-322.

12 Maki HE, Saramaki OR, Shatkina L, Martikainen PM, Tammela TL, van Weerden WM, Vessella RL, Cato AC, Visakorpi T: Overexpression and gene amplification of BAG-1L in hormone-refractory prostate cancer. J Pathol 2007;212:395-401.

13 Tang SC, Beck J, Murphy S, Chernenko G, Robb D, Watson P, Khalifa M: BAG-1 expression correlates with $\mathrm{Bcl}-2$, p53, differentiation, estrogen and progesterone receptors in invasive breast carcinoma. Breast Cancer Res Treat 2004;84:203-213.

- 14 Zapata JM, Krajewska M, Krajewski S, Huang RP, Takayama S, Wang HG, Adamson E, Reed JC: Expression of multiple apoptosis-regulatory genes in human breast cancer cell lines and primary tumors. Breast Cancer Res Treat 1998;47:129-140.

15 Brimmell M, Burns JS, Munson P, McDonald L, O'Hare MJ, Lakhani SR, Packham G: High level expression of differentially localized BAG-1 isoforms in some oestrogen receptor-positive human breast cancers. $\mathrm{Br} \mathrm{J}$ Cancer 1999;81:1042-1051.

16 Yang X, Hao Y, Ferenczy A, Tang SC, Pater A: Overexpression of anti-apoptotic gene BAG-1 in human cervical cancer. Exp Cell Res 1999;247:200-207.

$\checkmark 17$ Turner BC, Krajewski S, Krajewska M, Takayama S, Gumbs AA, Carter D, Rebbeck TR, Haffty BG, Reed JC: BAG-1: a novel biomarker predicting long-term survival in early-stage breast cancer. J Clin Oncol 2001;19:992-1000.

18 Townsend PA, Dublin E, Hart IR, Kao RH, Hanby AM, Cutress RI, Poulsom R, Ryder K, Barnes DM, Packham G: BAG-i expression in human breast cancer: interrelationship between BAG-1 RNA, protein, HSC70 expression and clinico-pathological data. J Pathol 2002;197:51-59.

19 Townsend PA, Cutress RI, Sharp A, Brimmell M, Packham G: BAG-1 prevents stress-induced long-term growth inhibition in breast cancer cells via a chaperone-dependent pathway. Cancer Res 2003;63:41504157.

20 Cutress RI, Townsend PA, Sharp A, Maison A, Wood L, Lee R, Brimmell M, Mullee MA, Johnson PW, Royle GT, Bateman AC, Packham G: The nuclear BAG-1 isoform, BAG-1L, enhances oestrogen-dependent transcription. Oncogene 2003;22:4973-4982. 
Liu et al.: BAG-1 Affects the Sensitivity of Breast Cancer Cells to Tamoxifen

21 Knowlden JM, Hutcheson IR, Jones HE, Madden T, Gee JM, Harper ME, Barrow D, Wakeling AE, Nicholson RI: Elevated levels of epidermal growth factor receptor/c-erbB2 heterodimers mediate an autocrine growth regulatory pathway in tamoxifen-resistant MCF-7 cells. Endocrinology 2003;144:1032-1044.

22 Tichopad A, Dilger M, Schwarz G, Pfaffl MW: Standardized determination of real-time PCR efficiency from a single reaction set-up. Nucleic Acids Res 2003;31:e122.

23 Chen J, Xiong J, Liu H, Chernenko G, Tang SC: Distinct BAG-1 isoforms have different anti-apoptotic functions in BAG-1-transfected C33A human cervical carcinoma cell line. Oncogene 2002;21:7050-7059.

24 Liu HY, Wang ZM, Bai Y, Wang M, Li Y, Wei S, Zhou QH, Chen J: Different BAG-1 isoforms have distinct functions in modulating chemotherapeutic-induced apoptosis in breast cancer cells. Acta Pharmacol Sin 200;30:235-241.

25 Ding Z, Yang X, Pater A, Tang SC: Resistance to apoptosis is correlated with the reduced caspase-3 activation and enhanced expression of antiapoptotic proteins in human cervical multidrug-resistant cells. Biochem Biophys Res Commun 2000;270:415-420.

26 Paik S, Shak S, Tang G, Kim C, Baker J, Cronin M, Baehner FL, Walker MG, Watson D, Park T, Hiller W, Fisher ER, Wickerham DL, Bryant J, Wolmark N: A multigene assay to predict recurrence of tamoxifen-treated, node-negative breast cancer. N Engl J Med 2004;351:2817-2826.

27 Millar EK, Anderson LR, McNeil CM, O'Toole SA, Pinese M, Crea P, Morey AL, Biankin AV, Henshall SM, Musgrove EA, Sutherland RL, Butt AJ: BAG-1 predicts patient outcome and tamoxifen responsiveness in ERpositive invasive ductal carcinoma of the breast. Br J Cancer 2009;100:123-133.

28 Hohfeld J, Jentsch S: GrpE-like regulation of the hsc70 chaperone by the anti-apoptotic protein BAG-1. EMBO J 1997;16:6209-6216.

29 Takayama S, Reed JC: Molecular chaperone targeting and regulation by BAG family proteins. Nat Cell Biol 2001;3:E237-241.

-30 Liu H, Liang Y, Li Y, Wang J, Wu H, Wang Y, Tang SC, Chen J, Zhou Q: Gene silencing of BAG-1 modulates apoptotic genes and sensitizes lung cancer cell lines to cisplatin-induced apoptosis. Cancer Biol Ther2010;9:832-840.

31 Tang S-C, Huang Q, Chen J: Differential anti-apoptotic functions of BAG-1 isoforms in breast cancer cells in the presence of estrogen and anti-estrogen. Breast Can Res Treat 2004(abstract);88:73.

-32 Tang SC: BAG-1, an anti-apoptotic tumour marker. IUBMB Life 2002;53:99-105.

-33 Froesch BA, Takayama S, Reed JC: BAG-1L protein enhances androgen receptor function. J Biol Chem 1998;273:11660-11666.

34 Kullmann M, Schneikert J, Moll J, Heck S, Zeiner M, Gehring U, Cato AC: RAP46 is a negative regulator of glucocorticoid receptor action and hormone-induced apoptosis. J Biol Chem 1998;273:14620-14625.

-35 Takahashi N, Sasaki R, Takahashi J, Takayama S, Reed JC, Andoh T: BAG-1M, an isoform of Bcl-2-interacting protein BAG-1, enhances gene expression driven by CMV promoter. Biochem Biophys Res Commun 2001;286:807-814.

-36 Afentakis M, Dowsett M, Sestak I, Salter J, Howell T, Buzdar A, Forbes J, Cuzick J: Immunohistochemical BAG1 expression improves the estimation of residual risk by IHC4 in postmenopausal patients treated with anastrazole or tamoxifen: a TransATAC study. Breast Cancer Res Treat 2013;140:253-262. 